\title{
Development of a water based process for stable conversion cathodes on the basis of $\mathrm{FeF}_{3}$
}

Alexander Pohl ${ }^{*}$,, Andreas Schröder ${ }^{a, b}$, Michael Baunach $^{b}$, Saman Faraz ${ }^{a}$, Alexander Guda ${ }^{c}$, Viktor $^{2}$ Shapovalov ${ }^{c}$, Kiran Chakravadhanula ${ }^{d}$, Ralf Witte ${ }^{a}$, Thomas Diemant ${ }^{e}$, Herman Emerich $^{f}$ and Maximilian Fichtner ${ }^{\mathrm{a}, \mathrm{d}}$

${ }^{a}$ Institute of Nanotechnology, Karlsruhe Institute of Technology, P.O. Box 3640, 76021 Karlsruhe, Germany

${ }^{b}$ Institute of Thermal Process Engineering, Thin Film Technology, Karlsruhe Institute of Technology, P.O. Box 3640, 76021 Karlsruhe, Germany

'International Research Center "Smart Materials", Southern Federal University, 5 Zorge St., 344090 Rostov-on-Don, Russian Federation

${ }^{d}$ Helmholtz Institute Ulm (HIU), Helmholtzstr. 11, 89081 Ulm, Germany.

e Institute of Surface Chemistry and Catalysis, Ulm University, Albert-Einstein-Allee 47, 89069 Ulm, Germany

${ }^{f}$ Swiss-Norwegian Beamline, European Synchrotron Radiation Facility, BP 220, 38043 Grenoble, France

*corresponding author: alexander.pohl@kit.edu

Fax: +49 721608 28298; Tel: +4972160826377

\section{Abstract}

A facile water based synthesis method for $\mathrm{HTB}-\mathrm{FeF}_{3} / \mathrm{rGO}$ and $r-\mathrm{FeF}_{3} / \mathrm{rGO}$ composites was developed using $\mathrm{FeF}_{3}$ nanoparticles prepared by ball-milling and aqueous graphene oxide precursor. Electrodes of $\mathrm{HTB}_{\mathrm{TeF}} / \mathrm{rGO}$ were cast in ambient air and the calendared electrode showed a stable specific energy of $470 \mathrm{Wh} \mathrm{kg}^{-1}\left(210 \mathrm{mAh} \mathrm{g}^{-1}, 12 \mathrm{~mA} \mathrm{~g}^{-1}\right)$ after 100 cycles in the range 4.3-1.3 $\mathrm{V}$ with very little capacity fading. The good cycle stability is attributed to the intimate contact of $\mathrm{FeF}_{3}$ nanoparticles with reduced graphene oxide carbon surrounding. We show using a combination of in situ XRD, XAS

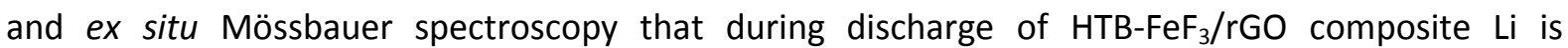

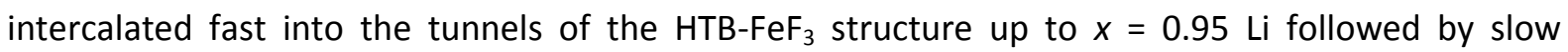
conversion to LiF and Fe nanoparticles below 2.0 V. During charge, the LiF and Fe phases are slowly

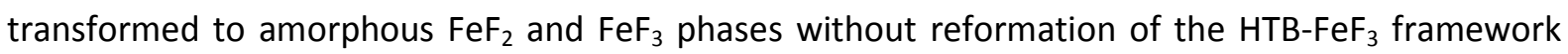
structure. At an elevated temperature of $55{ }^{\circ} \mathrm{C}$ a much higher specific energy of $780 \mathrm{Wh} \mathrm{kg}^{-1}$ was obtained. 


\section{Introduction}

The energy density (gravimetric and volumetric) of fossil fuels such as gasoline, diesel and, when extracted from natural gas also hydrogen, is about 50-100 times higher than that of current Li-ion, $\mathrm{NiMH}$ and lead acid batteries. ${ }^{1}$ This explains why it is tremendously difficult to develop full cell battery electric vehicles (BEV's), which have the same or nearly the same driving range (800-1200 $\mathrm{km}$ ) than that of traditional automobiles based on the internal combustion engine. Recently, the US department of energy has defined a new target for electrochemical storage devices for automotive applications. ${ }^{2}$ For a car to reach a driving range of 300 miles (ca. $480 \mathrm{~km}$ ), the battery needs to have an energy density of $250 \mathrm{Wh} \mathrm{kg}^{-1}$ at system level, which is 2.5 times higher than state-of-the-art battery packs currently in use for BEV's. ${ }^{3}$ After taking losses related to the electrode formulation (binder, carbon additives), electrode casting (thickness of active layer and current collector, porosity), cell construction (prismatic, pouch or round) and battery stack assembly (battery management, cooling etc.) into account, the electrode material is required to have a practical energy density of 700-800 $\mathrm{Wh} \mathrm{kg}^{-1}$ at high C-rates.

Conversion materials, with the general formula $\mathrm{M}^{n+} \mathrm{X}_{n}+n \cdot \mathrm{e}^{-}+n \cdot \mathrm{Li}^{+} \leftrightarrows \mathrm{M}^{0}+n \cdot \mathrm{LiX}$ and the ability to transfer more than one electron per transition metal $(n>1)$, are considered as next generation high capacity cathode materials. ${ }^{3,4}$ In a conversion material, $\mathrm{M}$ is usually a $3 d$ transition metal and $X^{\mathrm{n}-}$ an anion such $\mathrm{H}^{-}, \mathrm{O}^{2-}, \mathrm{F}^{-}, \mathrm{S}^{2-}$ and $\mathrm{Se}^{2-5}$. The battery is usually constructed in the charged state and on discharge, the metal fluoride, metal oxide etc. is transformed into metal nanoparticles $\mathrm{M}^{0}$ dispersed in an insulating matrix of LiX. ${ }^{6}$ Conversion materials based on metal fluorides are particularly interesting, because of the strong $\mathrm{M}-\mathrm{F}$ bond, some of them such as $\mathrm{FeF}_{3}, \mathrm{CoF}_{3}, \mathrm{NiF}_{3}$ and $\mathrm{CuF}_{2}$ have a high operating voltage ( $>2.5 \mathrm{~V}$ ) suitable as cathodes. ${ }^{7}$ Iron fluoride is particularly interesting because it has the highest theoretical energy density of $1950 \mathrm{Wh} \mathrm{kg}^{-1}\left(2.74 \mathrm{~V}, 712 \mathrm{mAh} \mathrm{g}^{-1}\right)$ and is non-toxic, environmentally friendly, cheap and abundant. ${ }^{8}$

Traditionally, $\mathrm{FeF}_{3} / \mathrm{C}$ composites have been prepared by ball-milling commercial rhombohedral $r$ $\mathrm{FeF}_{3}$ with carbon black to reduce the primary particle size and to coat the $r$ - $\mathrm{FeF}_{3}$ nanoparticles with an electrically conducting layer of carbon. ${ }^{9}$ This approach leads to materials with large initial capacity up to the theoretical maximum of $712 \mathrm{mAh} \mathrm{g}^{-1}$, but poor cycle stability as the carbon coating is incomplete and not attached strongly enough to the $\mathrm{FeF}_{3}$ particle surface. The carbon shell "peels off" during prolonged cycling due to pulverisation of the electrode (repeated formation of $\mathrm{Fe} / \mathrm{LiF}$ phases). To improve cycle stability, graphene oxide has been recently utilised in a number of publications to enable $r-\mathrm{FeF}_{3} / \mathrm{rGO}$ composite materials with strong $\mathrm{FeF}_{3} /$ carbon interactions. ${ }^{8,10-14}$ For example, Liu et al. ${ }^{11}$ have prepared a $r-\mathrm{FeF}_{3} / \mathrm{rGO}$ composite consisting of in-situ grown $\mathrm{FeF}_{3} \cdot 3 \mathrm{H}_{2} \mathrm{O}$ anchored on HF-etched graphene sheets. After removal of water, the $r-\mathrm{FeF}_{3} / \mathrm{rGO}$ composite shows a 
remarkably high capacity of $210 \mathrm{mAh} \mathrm{g}^{-1}$ when cycled between 2.0 and $4.5 \mathrm{~V}(\mathrm{C} / 5)$ and $490 \mathrm{mAh} \mathrm{g}^{-1}$ when cycled in the range 1.5-4.5 $\mathrm{V}(\mathrm{C} / 10)$. The good cycle performance of this composite can be attributed to the high electronic conductivity and the low ionic resistance of the graphene sheets. Using a facile self-assembly approach, Zhao et al. ${ }^{10}$ have prepared free-standing $r-\mathrm{FeF}_{3} / \mathrm{rGO}$ paper from $\mathrm{FeF}_{3}$ nanoparticles and graphene oxide water suspension followed by photothermal reduction. The ability to self-assemble the $r-\mathrm{FeF}_{3} / \mathrm{rGO}$ paper was attributed to attracting forces of $\mathrm{FeF}_{3}$ nanoparticles, which are strongly hydrophilic and have a positive surface charge (zeta potential = $34(1) \mathrm{mV}$ ) and negatively charged graphene oxide suspension (zeta potential $=-57(5) \mathrm{mV}$ ). The freestanding $r-\mathrm{FeF}_{3} / \mathrm{rGO}$ paper used directly as cathode shows initial high capacity of $587 \mathrm{mAh} \mathrm{g}^{-1}$ (20 mA $\mathrm{g}^{-1}$ ), but cycle stability is poor with quick capacity fading after 20 cycles due to the special architecture of the free-standing $r-\mathrm{FeF}_{3} / \mathrm{rGO}$ paper.

Iron-fluoride based nanomaterials with orthorhombic hexagonal-tungsten-bronze (HTB) structure were reported by $\mathrm{Li}$ and co-workers ${ }^{15-19}$ and prepared using a non-aqueous approach in an ionic liquid medium. The $\mathrm{HTB}-\mathrm{FeF}_{3} \cdot 0 \cdot 33 \mathrm{H}_{2} \mathrm{O}$ material shows an interesting sponge-like morphology with needles on the surface and high Li-ion mobility. When considered as Li-intercalation host, HTB$\mathrm{FeF}_{3} .0 .33 \mathrm{H}_{2} \mathrm{O}$ can store up to $0.66 \mathrm{Li}$ per formula unit $\left(156 \mathrm{mAh} \mathrm{g}^{-1}\right)$ and a reversible capacity of 130 mAh $\mathrm{g}^{-1}$ was observed in the range 1.6-4.5 $\mathrm{V}^{15}$ The stability of the $\mathrm{HTB}^{1} \mathrm{FeF}_{3} \cdot 0.33 \mathrm{H}_{2} \mathrm{O}$ framework structure towards Li insertion was attributed to the presence of zeolitic water in the channels.

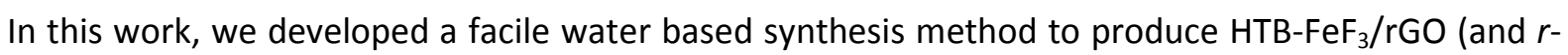
$\mathrm{FeF}_{3} / \mathrm{rGO}$ ) nanocomposites using aqueous graphene oxide suspension and $\mathrm{FeF}_{3}$ nanoparticles. The

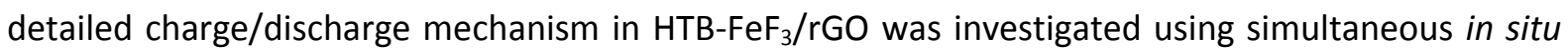
X-ray absorption spectroscopy (XAS) above the Fe K-edge, X-ray diffraction (XRD) and ex-situ Mössbauer spectroscopy. The combination of such methods determines unambiguously the charge state of $\mathrm{Fe}$, the cycle life of initial crystalline $\mathrm{HTB}^{-\mathrm{FeF}_{3}}$ phase and the Fe local surrounding. ${ }^{20,21}$

\section{Experimental}

Synthesis of graphene oxide: Graphene oxide (GO) was used as a precursor for $\mathrm{FeF}_{3} / \mathrm{rGO}$ composite materials and prepared from natural graphite flakes using a modified Hummer's method as described previously. ${ }^{10}$ For BET and SEM analysis, a fine GO powder was obtained by heating the GO suspension in $\mathrm{NaOH}$ followed by treatment in $\mathrm{HCl}$ as described in Dreyer et al. ${ }^{22}$

Synthesis of $\mathrm{HTB}_{\mathrm{FeF}} / \mathrm{rGO}$ and $r-\mathrm{FeF}_{3} / \mathrm{rGO}$ composites: The $\mathrm{FeF}_{3} / \mathrm{rGO}$ composite materials were prepared by using ball milled commercial $r$ - $\mathrm{FeF}_{3}$ (Sigma-Aldrich, $98 \%$ ) and aqueous GO suspension

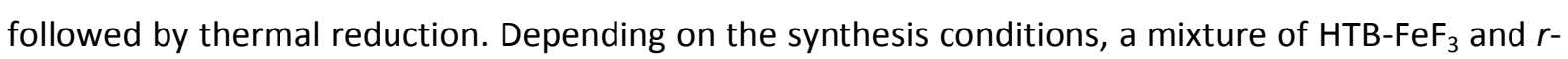


$\mathrm{FeF}_{3}$ polymorphs were obtained (Table 1). Details of the synthesis procedure can be found in the supplement.

Physical characterisation: The elemental concentrations of $\mathrm{Fe}$ and $\mathrm{S}$ were determined using inductive coupled plasma-optical emission spectroscopy (ICP-OES). Laboratory powder X-ray diffraction patterns were collected using a STOE Stadi P diffractometer equipped with a Dectris Mythen $1 \mathrm{~K}$ linear silicon strip detector and $\mathrm{Ge}(111)$ double crystal monochromator (Mo $\mathrm{K}_{\alpha 1}, \lambda=$ $0.7093 \AA$ A in Debye-Scherrer geometry. Samples were filled into $0.7 \mathrm{~mm}$ borosilicate capillaries and data was collected between $3-63^{\circ} 2 \theta$. The mass fractions of crystalline phases were determined by the Rietveld method using the TOPAS academic software. ${ }^{23}$ Mössbauer spectra were recorded using a constant acceleration-type spectrometer in transmission geometry with a moving source of ${ }^{57} \mathrm{Co}$ in a Rh matrix. Approximately $50 \mathrm{mg}$ material was sealed into a plastic bag inside an argon filled glove box. The isomer shift is given relative to $\alpha$-Fe at room temperature.

Morphological characterisation: SEM micrographs were recorded at $10 \mathrm{kV}$ using a Zeiss Leo-1530 scanning electron microscope (InLens detector) equipped with an Oxford Instruments X-max ${ }^{\mathrm{N}}$ EDX detector. TEM characterisation was carried out using an aberration corrected FEI Titan 80-300 transmission electron microscope equipped with a Gatan imaging filter (Tridiem 863) operated at 80 kV. Samples were prepared by dispersing a small amount of powder onto holey carbon Au grids (Quantifoil) inside an argon filled glove box and transferred under Ar to the sample chamber using a Gatan vacuum transfer holder.

Electrochemical characterisation: Galvanostatic charge/discharge experiments of $\mathrm{FeF}_{3} / \mathrm{rGO}$ cathodes versus Li-metal anode were performed using Swagelok-type cells and CR2032 coin cells. For Swagelok cells, the powders were mixed with 10 wt.\% carbon black and used directly without casting. For coin cells, a slurry was prepared and the material cast onto Al foil. Details of the electrode preparation are given in the supplement.

In situ XAS/XRD characterisation: Simultaneous X-ray absorption spectra and diffraction patterns were recorded in situ at the Swiss-Norwegian Beamline (BM01B) of the European Synchrotron Radiation Facility (ESRF), Grenoble, France. The home-built battery cells with glassy carbon windows transparent for X-rays were constructed as described previously. ${ }^{21}$ Two cells were installed in parallel on a rotational stage and galvanostatic charge/discharge curves recorded using Gamry Interface 1000 potentiostats with a constant current of $50 \mu \mathrm{A}$. On each cell, diffraction was recorded for 15 minutes followed by Fe K-edge absorption for 20 minutes, then the stage was turned $180^{\circ}$ for the other cell and data collection was resumed. Ten 2D diffraction images were recorded with 5 seconds acquisition time by the CMOS-Dexela 2D detector. Both the wavelength $\lambda=0.50574 \AA$ and the 
sample-to-detector distance of $324.05 \mathrm{~mm}$ were calibrated using $\mathrm{LaB}_{6}$ and silicon powder standards. Subsequent averaging and integration were carried out using Fit2D software. ${ }^{24}$ Fe K-edge X-ray absorption spectra were measured in transmission mode employing a Si(111) monochromator in continuous scanning mode. Ionization chambers were used to monitor intensity before and after sample and Fe foil was measured simultaneously with the sample as a reference compound to monitor possible energy drift.

Theoretical methods: The series of Fe K-edge XANES spectra collected at different voltages were mathematically decomposed into spectra representing phases formed during charge/discharge using principle component analysis (PCA) ${ }^{25,26}$ as implemented into Fitlt software. ${ }^{27}$ The concentrations of the components and spectra itself were determined using physical constraints: spectra should be normalized, the values of concentrations should be positive, two of three components under consideration should represent initial $\mathrm{FeF}_{3}$ state and final Fe state of composite material.

\section{Results and discussion}

The $\mathrm{HTB}_{-} \mathrm{FeF}_{3} / \mathrm{rGO}$ and $r-\mathrm{FeF}_{3} / \mathrm{rGO}$ composites were synthesised using an aqueous graphene oxide water suspension and commercial $\mathrm{FeF}_{3}$ as described in experimental section. Depending on the synthesis conditions (pre ball-milled vs. as received $\mathrm{FeF}_{3}$, temperature, grinding vs. post ball-milling), the composites contained a mixture of rhombohedral $\mathrm{FeF}_{3}$ and hexagonal-tungsten-bronze-type $\mathrm{HTB} \mathrm{FeF}_{3}$ polymorphs with varying weight fractions and a small amount of WC $(<1 \mathrm{wt} . \%)$ introduced by abrasion during ball-milling process (Table 1 ). Using pre ball-milled nanocrystalline $\mathrm{FeF}_{3}$, the majority of $r-\mathrm{FeF}_{3}$ was transformed to $\mathrm{HTB}-\mathrm{FeF}_{3}$, whereas using the $r-\mathrm{FeF}_{3}$ as received, the amount of $\mathrm{HTB}-\mathrm{FeF}_{3}$ in the composites was much less. The water based graphene oxide process is scalable, HFfree and a variable amount of reduced graphene oxide $(\mathrm{rGO})$ carbon can be introduced by varying the amount and concentration of GO suspension. This is an advantage, as the optimal carbon content is fine-tuneable for production of a commercial material with an optimal electrical conductivity and gravimetric capacity. The $\mathrm{HTB}^{-\mathrm{FeF}_{3}}$ structure has large hexagonal channels along the $c$-axis which can accommodate additional lattice water (Figure 1). Refinement of the 0

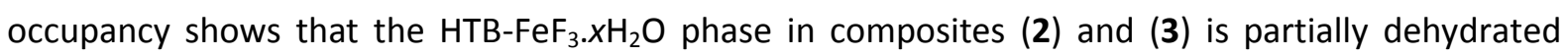
with $x=0.28$ (2) and $x=0.09$ (3), respectively. The removal of lattice water is also indicated by a slight contraction of the $a$-axis (5.3\%o (2), $3.5 \%$ (3)) and expansion of the $c$-axis (1.1\%o (2), $2.0 \%$ (3)). 
Table 1: Synthesis conditions and Rietveld refinement parameters. Pre-BM: ball-milling of commercial $\mathrm{FeF}_{3}$ before mixing with $\mathrm{GO}$ suspension, Post-BM: ball milling of composite material after manual grinding, reduction temperature and time, ICP-OES element concentrations of Fe and $\mathrm{S}$, $\mathrm{FeF}_{3}$ amount calculated from ICP-OES, $r-\mathrm{FeF}_{3}$ and $\mathrm{HTB}^{-\mathrm{FeF}_{3}}$ phase fractions from Rietveld refinement,

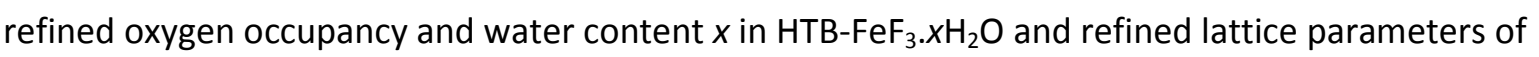

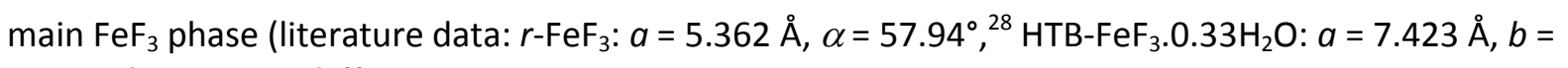
$12.730 \AA, c=7.526 \AA)^{29}$.

\begin{tabular}{|c|c|c|c|c|c|c|c|c|c|c|c|}
\hline No. & $\begin{array}{l}\text { pre- } \\
\text { BM }\end{array}$ & $\begin{array}{l}\text { post- } \\
\text { BM }\end{array}$ & $\begin{array}{l}\text { Temp. } \\
{ }^{\circ} \mathrm{C}\end{array}$ & $\begin{array}{l}\text { Time } \\
\mathrm{h}\end{array}$ & $\begin{array}{l}\text { Fe } \\
\text { wt.\% }\end{array}$ & $\begin{array}{l}\text { S } \\
\text { wt.\% }\end{array}$ & $\begin{array}{l}\mathrm{FeF}_{3} \\
\text { wt.\% }\end{array}$ & $\begin{array}{l}r-\mathrm{FeF}_{3} \\
\text { wt.\% }\end{array}$ & $\begin{array}{l}\text { HTB-FeF } \\
\text { wt.\% }\end{array}$ & $\begin{array}{l}\mathrm{O} \text { occ., } \\
x \mathrm{H}_{2} \mathrm{O}\end{array}$ & $\begin{array}{l}\text { Refined LP's } \\
\AA,{ }^{\circ}\end{array}$ \\
\hline 1 & - & - & 300 & 4 & 32.2 & 6.6 & 65.5 & $89(1)$ & 11(1) & - & $a: 5.3558(5)$ \\
\hline 2 & $x$ & - & 200 & 12 & 40.0 & 2.7 & 84.6 & $11.5(4)$ & $88.5(4)$ & $\begin{array}{l}0.84(1), \\
0.28\end{array}$ & $\begin{array}{l}a: 7.384(3) \\
b: 12.780(5) \\
c: 7.5339(5)\end{array}$ \\
\hline 3 & $x$ & $x$ & 200 & 12 & 40.7 & - & 82.2 & $20.9(4)$ & 77.1(4) & $\begin{array}{l}0.26(1), \\
0.09\end{array}$ & $\begin{array}{l}a: 7.397(1) \\
b: 12.761(2) \\
c: 7.5412(6)\end{array}$ \\
\hline
\end{tabular}

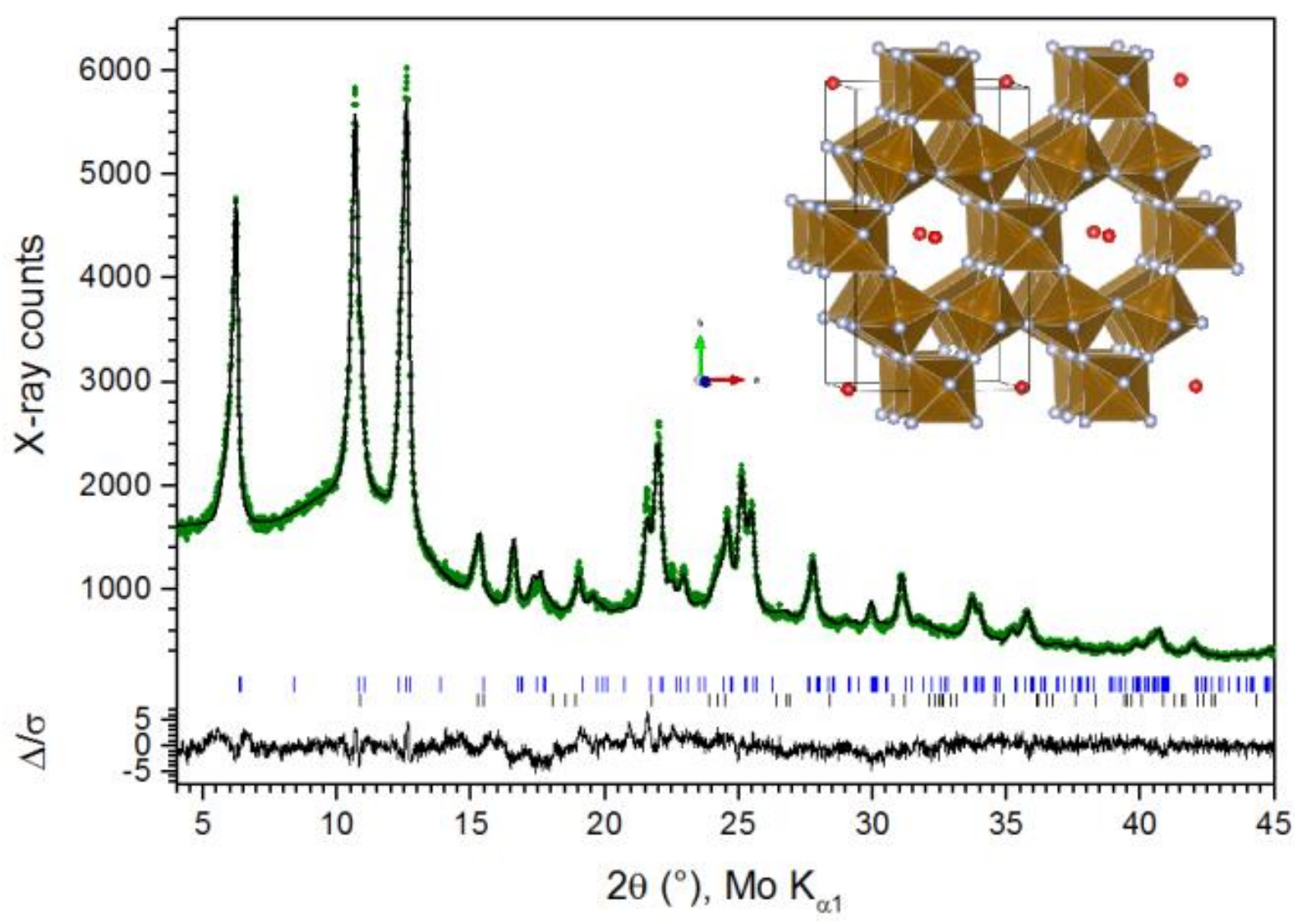

Figure 1: Rietveld refinement of $\mathrm{HTB}_{-} \mathrm{FeF}_{3} / \mathrm{rGO}(2)$ composite $(\lambda=0.7093 \AA)$. The green dots correspond to experimental data, the black line is the calculated fit. The blue and black tick marks

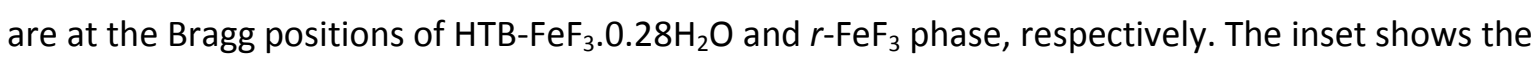


the $\mathrm{HTB}^{-\mathrm{FeF}_{3}}$ structure ${ }^{29}$ with hexagonal tunnels along the $c$-axis filled $1 / 3$ with water molecules (red spheres).

\section{Electrochemical performance}

The electrochemical performance of the composites (1-3) was found to be very similar after the first cycle irrespective of the amount of $\mathrm{HTB}-\mathrm{FeF}_{3}$ and $r-\mathrm{FeF}_{3}$ polymorphs present. Electrodes of HTB$\mathrm{FeF}_{3} / \mathrm{rGO}$ (2) composite were prepared using a self-made batch coating machine with a custom designed slot nozzle dryer. The hygroscopic $\mathrm{FeF}_{3}$ is well protected by the $\mathrm{rGO}$ carbon from ambient moisture enabling casting on the bench without affecting the performance of the electrode. This is beneficial as no special dry-room or inert gas conditions are required to produce high-quality, production-grade electrodes from these materials. The electrochemical performance of HTB$\mathrm{FeF}_{3} / \mathrm{rGO}(2)$ is shown in Figure 2 . The composite was cycled at two different temperatures using as-

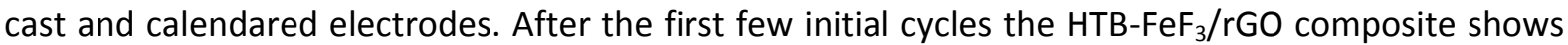
excellent cycle stability compared to a $r-\mathrm{FeF}_{3}$ composite prepared by ball milling with an equivalent amount of carbon black (HTB-FeF 3 (2): 22 wt.\% rGO and extra CB, $r$-FeF: 30 wt.\% CB). The as cast $\mathrm{HTB} \mathrm{FeF}_{3} / \mathrm{rGO}$ electrode shows a stable discharge energy of $368 \mathrm{Wh} \mathrm{kg}^{-1}\left(166 \mathrm{mAh} \mathrm{g}^{-1}, 12.8 \mathrm{~mA} \mathrm{~g} \mathrm{~g}^{-1}\right.$, black curve) at $25^{\circ} \mathrm{C}$ for 100 cycles with negligible capacity fading after the $40^{\text {th }}$ cycle. The stable cycle performance is attributed to a very firm contact of $\mathrm{FeF}_{3}$ particles with the electron conducting reduced graphene oxide environment. The good contact is an effect of the attracting forces of the positively charged $\mathrm{FeF}_{3}$ particle surface and negatively charged graphene oxide in water before drying. ${ }^{10}$ Calendaring the electrode increases the discharge energy by $29 \%$ to $474 \mathrm{Wh} \mathrm{kg}^{-1}$ (215 mAh $\mathrm{g}^{-1}$, cycle 40-100, blue curve) without affecting the long term cycle stability due to pulverisation of small $\mathrm{FeF}_{3}$ agglomerates present in the as cast electrode. Raising the temperature from $25^{\circ} \mathrm{C}$ to $40^{\circ} \mathrm{C}$ increases the specific energy also by $29 \%$ to $473 \mathrm{Wh} \mathrm{kg}^{-1}$ ( $222 \mathrm{mAh} \mathrm{g}^{-1}, 40-80$ cycles, pink curve). The conversion rate of $\mathrm{FeF}_{3}$ into LiF and $\mathrm{Fe}$ is accelerated due to higher ion mobility. However, after 80 cycles (not shown) the specific energy increases abnormally fast due to decomposition of the LiPF 6 electrolyte above $40^{\circ} \mathrm{C} .{ }^{30} \mathrm{Cycling}$ the calendared electrode at $40{ }^{\circ} \mathrm{C}$ gives a specific energy increase of $59 \%$ to $586 \mathrm{Wh} \mathrm{kg}^{-1}$ (277 mAh g${ }^{-1}, 40-60$ cycles, red curve) compared to the as cast electrode cycled at $25^{\circ} \mathrm{C}$

Rate capability tests of as cast and calendared $\mathrm{HTB}^{-\mathrm{FeF}_{3}}$ (2) electrodes were performed at two different temperatures and are shown in Figure $2 \mathrm{~b}$. The grey bar represents the specific energy target of $700-800 \mathrm{Wh} \mathrm{kg}^{-1}$ required for practical automotive batteries. ${ }^{3}$ Both calendaring and the elevated temperature has a beneficial effect on the rate performance. The calendared electrode cycled at $55^{\circ} \mathrm{C}$ shows a high average initial discharge energy of $900 \mathrm{Wh} \mathrm{kg}^{-1}\left(435 \mathrm{mAh} \mathrm{g}^{-1}, 17 \mathrm{~mA} \mathrm{~g}^{-1}\right)$ 
over cycles 2-4, which exceeds the target on materials level by $100-200 \mathrm{Wh} \mathrm{kg}^{-1}$. When the current density is raised to $0.84 \mathrm{~A} \mathrm{~g}^{-1}$ (equivalent to $1 \mathrm{C}$ ), the discharged energy dropped considerably to 180

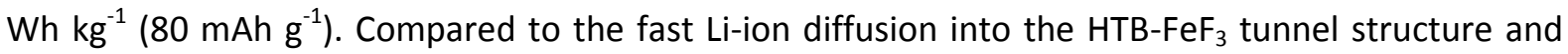

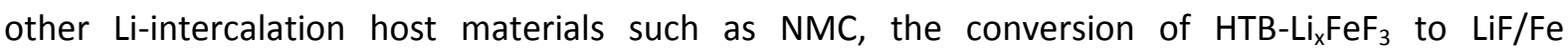
nanoparticles is slow leading to a kinetic limitation of the material. Considerable improvement was observed when raising the temperature (black and blue curves). After changing the discharge current back to its initial value of $17 \mathrm{~mA}^{-1}$, the electrode (calendared, $55^{\circ} \mathrm{C}$, red curve) lost $19 \%$ of its initial capacity probably due to deterioration of the $\mathrm{LiPF}_{6}$ electrolyte.
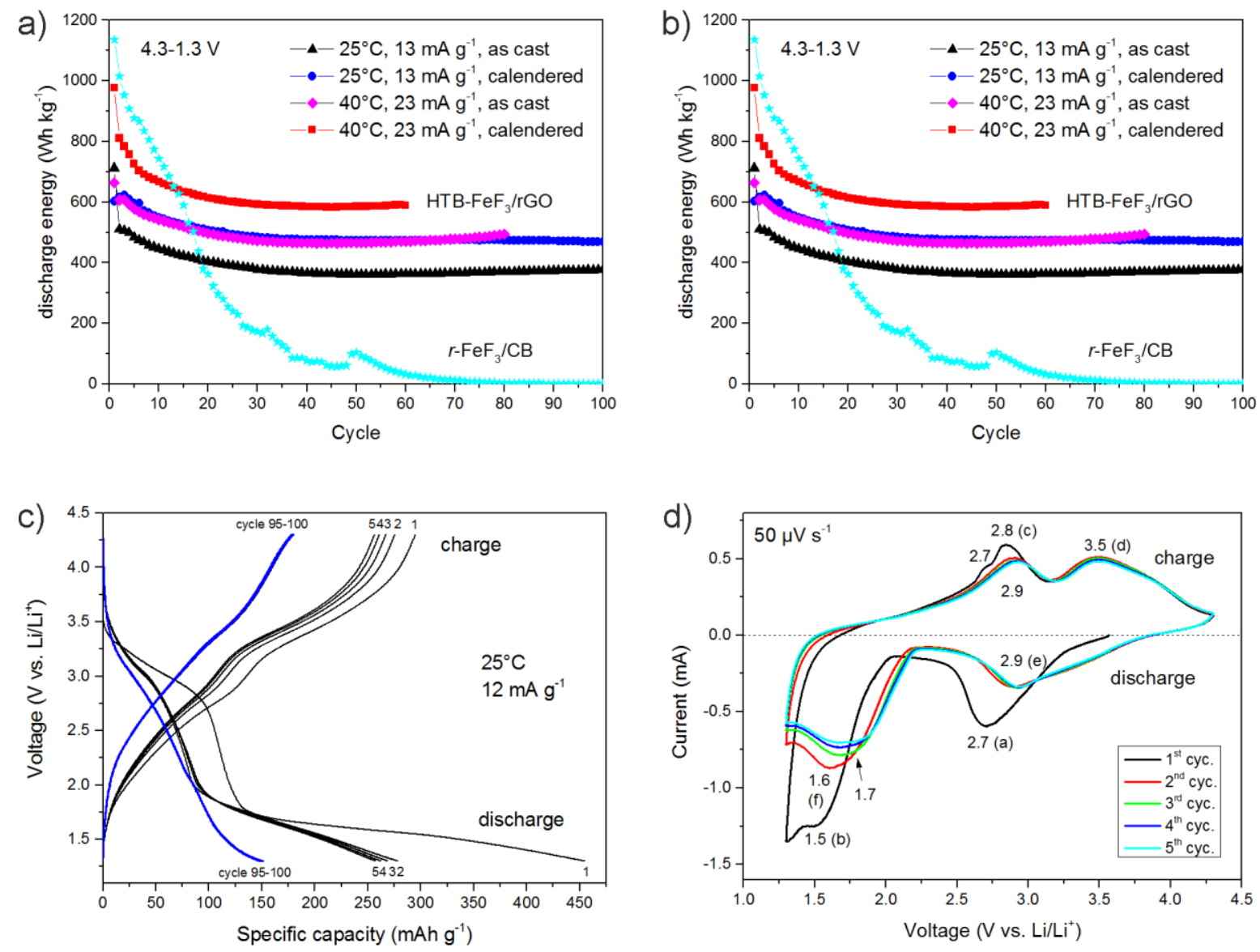

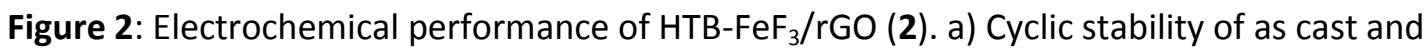
calendared films in coin cells at $25^{\circ} \mathrm{C}$ and $40^{\circ} \mathrm{C}$ in comparison with $\mathrm{FeF}_{3}$ ball milled with carbon black. b) Rate capability test of as cast and calendared films at $25^{\circ} \mathrm{C}$ and $55^{\circ} \mathrm{C}$. The grey bar indicates the target of 700-800 Wh/kg on materials level. ${ }^{3} \mathrm{c}$ ) Galvanostatic profile and d) cyclovoltammogram of powder in a Swagelok cell.

The galvanostatic charge/discharge profile shown in Figure $2 \mathrm{c}$ resembles that of $\mathrm{HTB}^{-}-\mathrm{FeF}_{3}$ in the first cycle and amorphous $\mathrm{FeF}_{3}$ in subsequent cycles as will be shown later. In the first cycle, there is a short plateau above $2.8 \mathrm{~V}$ where $\mathrm{Li}$ intercalation into the $\mathrm{HTB}^{-\mathrm{FeF}_{3}}$ tunnel structure takes place ${ }^{15,16}$ 


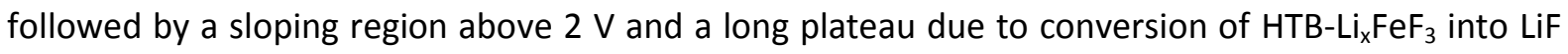
and Fe nanoparticles. In summary, the overall conversion reaction can be written as $\mathrm{FeF}_{3}+3 \cdot \mathrm{e}^{-}+$ 3. $\mathrm{Li}^{+} \leftrightarrows \mathrm{Fe}^{0}+3 \cdot \mathrm{LiF}$ leading to a theoretical capacity of $712 \mathrm{mAh} \mathrm{g}^{-1}\left(1950 \mathrm{Wh} \mathrm{kg}^{-1}\right)$ for the 3 electron transfer. There is a large irreversible capacity loss of $135 \mathrm{mAh} \mathrm{g}^{-1}$ in the first cycle due to formation of a solid electrolyte interface on the Li-metal anode ${ }^{31}$ or due to as yet unidentified reactions of the $\mathrm{FeF}_{3}$ cathode with the electrolyte. After complete discharge, the $\mathrm{HTB}^{-\mathrm{FeF}_{3}}$ is transformed into $\mathrm{Fe}$ metal nanoparticles embedded into an insulating matrix of LiF nanocrystallites. ${ }^{6}$ In subsequent cycles, the discharge plateau above $2.8 \mathrm{~V}$ is shortened considerably due to collapse of the HTB tunnel structure and subsequent formation of amorphous $\mathrm{FeF}_{3}$, which has less capacity for Li storage than the HTB framework structure.

The CV diagram in Figure $2 \mathrm{~d}$ clearly shows that the charge/discharge mechanism in the first cycle (black) differs from the storage mechanism in subsequent cycles (letters a-f correspond to regions defined in Figure 4). In the first cycle, the intercalation region a has a pronounced discharge peak with a maximum at $2.7 \mathrm{~V}$. In subsequent cycles, peak e is shifted from $2.7 \mathrm{~V}$ to $2.9 \mathrm{~V}$ and is much broader compared to the first cycle indicating a solid solution or surface charge storage mechanism rather than an intercalation process. The conversion regimes $\mathbf{b}$ and $\mathbf{c}$ are characterised by a large voltage hysteresis of approximately $1.2 \mathrm{~V}$ due to the phase transformations. ${ }^{32}$

\section{Microstructure}

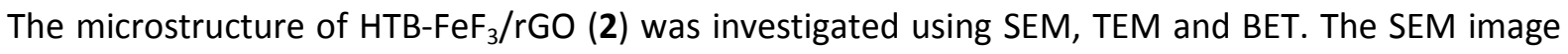
Figure 3a shows a large $\mathrm{HTB}_{\mathrm{T}} \mathrm{FeF}_{3} / \mathrm{rGO}$ particle with a textured surface covered by smaller HTB$\mathrm{FeF}_{3} / \mathrm{rGO}$ particles from top and side. EDX analysis (Figure S1, \$ESI) shows a strong overlap between $\mathrm{O}, \mathrm{C}$ and $\mathrm{F}$ elemental maps indicating that $\mathrm{HTB}^{-} \mathrm{FeF}_{3}$ particles are homogenously coated by graphite oxide. The HR-TEM micrograph (Figure $3 b$ ) shows graphitic carbon layers rolled into onion-like structures. The graphitic layers have an interlayer spacing of $d=3.5 \AA$, which is in good agreement with the $d$-spacing of reduced graphene oxide ${ }^{33}$ (but larger than $d=3.356(4) \AA$ reported for graphite $\left.^{34}\right)$. The enlarged interlayer distance shows that after oxidative/reductive treatment the natural graphite flakes are well exfoliated and the rGO layers contain lattice defects and residual oxygen groups on the surface which cause the layers to expand. Figure $3 c$ shows HTB-FeF 3 nanoparticles (dark areas) embedded into carbon (spheres). The SAED pattern (inset) is in good

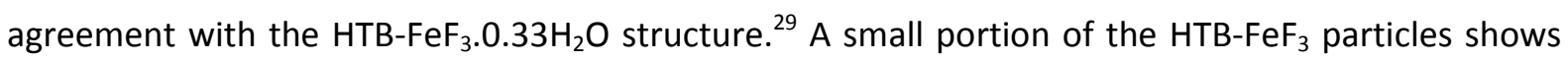
mesoporosity with an average pore diameter of $6 \mathrm{~nm}$ (Figure $3 \mathrm{~d}$ and Figure S2, \$ESI). However, the BET surface area of $20.1 \mathrm{~m}^{2} / \mathrm{g}$ and the cumulative pore volume of $0.04 \mathrm{~cm}^{3} / \mathrm{g}$ is small for a truly "porous" material indicating that the majority of $\mathrm{HTB}^{-\mathrm{FeF}_{3}}$ particles exist as a dense solid phase (Figure S3, \$ESI). These dense particles are not accessible by $\mathrm{N}_{2}$ molecules in BET measurements, but 
are involved in Li diffusion process during intercalation and conversion reactions. The $\mathrm{C}_{1 \mathrm{~s}} \mathrm{XPS}$ spectrum of $r-\mathrm{FeF}_{3} / \mathrm{rGO}$ (1) (Figure S4, \$ESI) consists of the same carbon functionalities found for graphene oxide ${ }^{35}$, but with reduced intensities of the $\mathrm{C}-\mathrm{O}$ and $\mathrm{C}=\mathrm{O}$ peaks indicating almost complete de-oxygenation by the reduction process. The combined TGA/DSC/MS analysis (Figure S5, \$ESI)

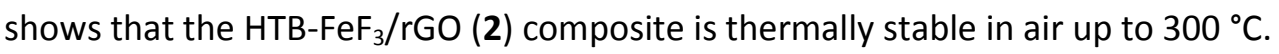

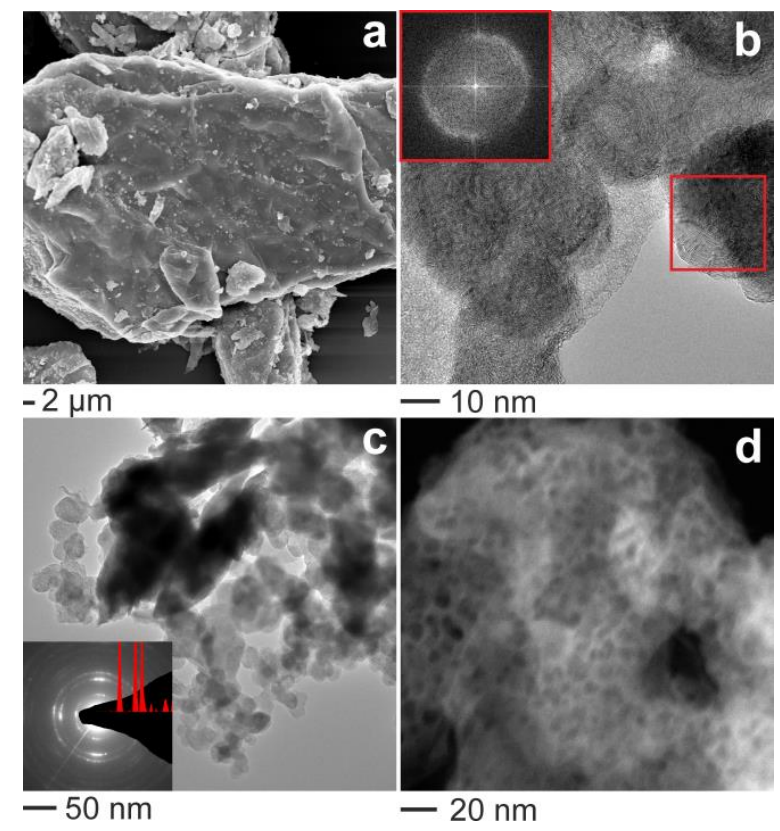

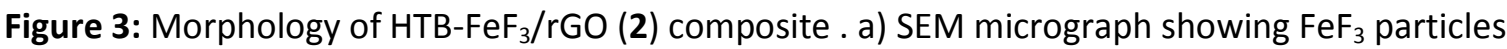
covered by layers of $\mathrm{rGO}$ carbon. b) HT-TEM micrograph of reduced graphene oxide ( $\mathrm{rGO}$ ) with SAED pattern of $\mathrm{rGO}\left(d=3.5 \AA\right.$ ) in inset. c) HR-TEM micrograph of $\mathrm{FeF}_{3}$ particles (light grey areas) embedded into $\mathrm{rGO}$ carbon (dark areas). The SAED pattern (inset) shows a diffractogram matching the first three intense reflections of the $\mathrm{HTB}^{-\mathrm{FeF}_{3}}$ structure (red bars). d) HAADF STEM image of a selected microporous $\mathrm{FeF}_{3}$ particle with an average pore diameter of $d=6 \AA$.

\section{Reaction mechanism}

To investigate Fe oxidation state changes and the phases formed during intercalation and conversion

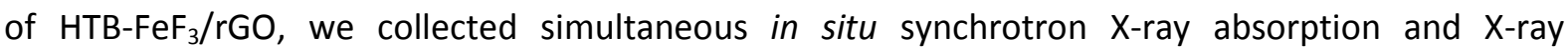
diffraction data and ex situ laboratory Mössbauer spectra at certain points in the $1^{\text {st }}$ and beginning of $2^{\text {nd }}$ cycle. Fe K-edge XANES and Mössbauer unambiguously determine the oxidation state of $\mathrm{Fe}$, and are able to provide structural information when compared to literature data and theoretical simulations. On the other hand, XRD is able to detect changes in the long-range order as $L i$ is intercalated. Figure 4 shows the voltage profile with points where ex situ Mössbauer spectra have been collected, the Fe concentration profile calculated from the Fe K-edge XANES spectra using principle component analysis, and a contour plot of X-ray diffraction data. All XANES spectra were 
decomposed by the Principal Component Analysis (PCA) method into three subspectra, which correspond to $\mathrm{Fe}, \mathrm{FeF}_{2}$ and $\mathrm{FeF}_{3}$ phases (Figure $\mathrm{S} 6, \mathbf{S S I}$ ). A summary of best guess structural phases determined with each technique is given in Table 2 and will be discussed in the following paragraphs.

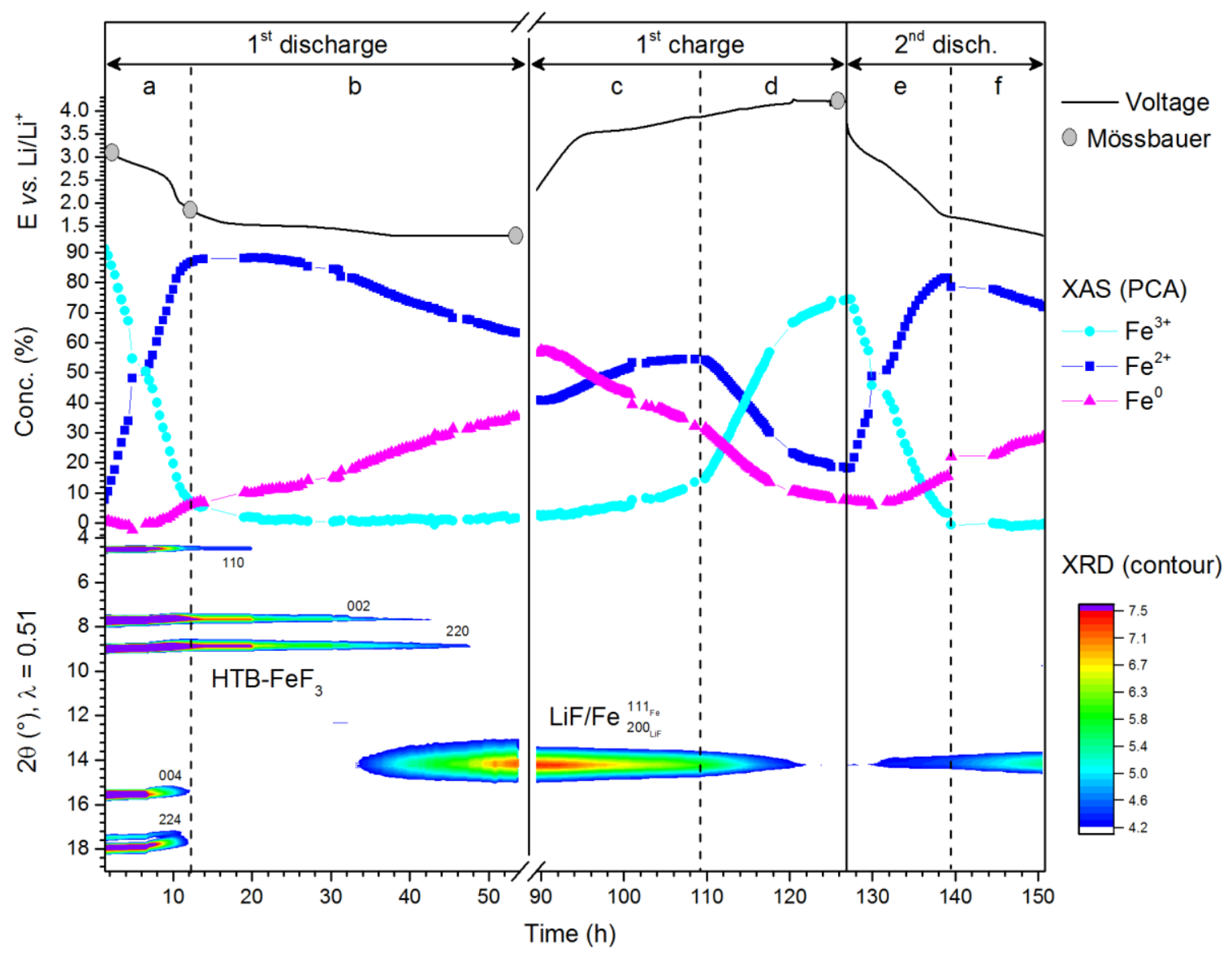

Figure 4: In situ XAS/XRD experiment of $\mathrm{HTB}_{\mathrm{THeF}} / \mathrm{rGO}$ (3) composite. Voltage profile during charge/discharge of the cell with grey circles indicating points where ex situ Mössbauer spectra were collected (top), PCA concentration profile of $\mathrm{Fe}, \mathrm{Fe}^{2+}$ and $\mathrm{Fe}^{3+}$ components obtained from simultaneous decomposition of $260 \mathrm{Fe}$ K-edge XANES spectra (middle) and XRD contour plot $(\lambda=$ $0.51 \AA ̊$ ) showing evolution of $\mathrm{HTB}^{-\mathrm{FeF}_{3}}$, LiF and Fe phases during charge/discharge (bottom).

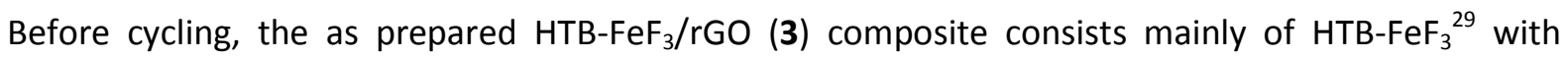
hexagonal tungsten bronze structure and large hexagonal channels along the $c$-axis (Figure 1). The channels are almost completely dehydrated $\left(0.09 \mathrm{H}_{2} \mathrm{O}\right)$ and there is space to accommodate further $\mathrm{Li}$ atoms in the tunnels. ${ }^{16}$ The XAS spectrum shows a $\mathrm{Fe}^{3+}$ oxidation state and the spectrum resembles

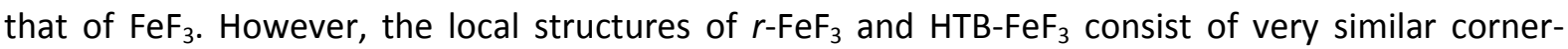
sharing $\mathrm{FeF}_{6}$ octahedra and cannot be easily distinguished by XAS. The Mössbauer spectrum (Figure

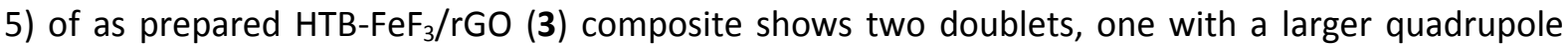


splitting (QS) of $0.5(2) \mathrm{mm} \mathrm{s}^{-1}$ and one with a smaller QS of $0.22(2) \mathrm{mm} \mathrm{s}^{-1}$ (Table 3). The large $\mathrm{Fe}^{3+}$ doublet is in good agreement with the fully hydrated structure $\mathrm{HTB}-\mathrm{FeF}_{3} \cdot 0.33 \mathrm{H}_{2} \mathrm{O}$ with $1 / 3$ water in the channels. ${ }^{29}$ The small Fe ${ }^{3+}$ doublet may be due to the partial removal of $\mathrm{H}_{2} \mathrm{O}$ molecules from the

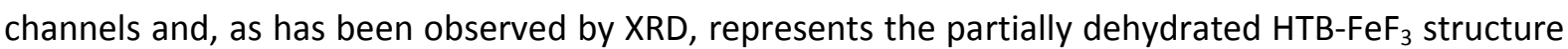
reported by Calage et al. ${ }^{36}$ The Mössbauer spectrum also indicates the presence of a small amount of $r-\mathrm{FeF}_{3}$ (3\% ra) with a large magnetic hyperfine splitting of $40.4 \mathrm{~T}^{37}$ in agreement with the XRD refinement (Table 1). Additionally, there is an $\mathrm{Fe}^{2+}$ component (7\% ra) with an isomer shift of $1.14(2)$ $\mathrm{mm} \mathrm{s}^{-1}$ and a large QS of $2.56 \mathrm{~mm} \mathrm{~s}^{-1}$. These parameters suggest some form of nanocrystalline $\mathrm{FeF}_{2}{ }^{38}$. It is known that $r-\mathrm{FeF}_{3}$ is not stable under high-energy ball milling conditions and tends to partially reduce to $\mathrm{FeF}_{2} \cdot{ }^{39}$ However, the particle size of $\mathrm{FeF}_{2}$ must be very small as no additional macroscopic $\mathrm{FeF}_{2}$ phase was identified in the XRD pattern.

Table 2: Best guess structural phases found in $\mathrm{HTB}^{-}-\mathrm{FeF}_{3} / \mathrm{rGO}$ (3) composite during cycling. Numbers in parenthesis: PCA concentrations, XRD phase fraction in wt.\% and Mössbauer relative area.

\begin{tabular}{|c|c|c|c|}
\hline & XAS & XRD & Mössbauer \\
\hline \multirow[t]{4}{*}{ as prepared } & $\mathrm{Fe}^{3+}(91)$ & $\mathrm{HTB}-\mathrm{FeF}_{3}(77)$ & $\mathrm{FeF}_{3} \cdot 0.33 \mathrm{H}_{2} \mathrm{O}(62)$ \\
\hline & $\mathrm{Fe}^{2+}(8)$ & $r-\mathrm{FeF}_{3}(21)$ & HTB-FeF 3 (28) \\
\hline & $\mathrm{Fe}^{0}(1)$ & WC (2) & $n-\mathrm{FeF}_{2}$, bulk (7) \\
\hline & & & $r-\mathrm{FeF}_{3}(3)$ \\
\hline \multirow[t]{2}{*}{ dc $3.0 \mathrm{~V}$} & $\mathrm{Fe}^{3+}(78)$ & HTB-Li $\mathrm{FeF}_{3}$ & $\mathrm{Fe}^{3+}(58)$ \\
\hline & $\mathrm{Fe}^{2+}(22)$ & & $\mathrm{Fe}^{2+}(42)$ \\
\hline \multirow[t]{3}{*}{ dc $1.9 \mathrm{~V}$} & $\mathrm{Fe}^{2+}(86)$ & HTB-Li ${ }_{x} \mathrm{FeF}_{3}$ & $\mathrm{Fe}^{2+}(80)$ \\
\hline & $\mathrm{Fe}^{3+}(8)$ & & $\mathrm{Fe}^{3+}(20)$ \\
\hline & $\mathrm{Fe}^{0}(6)$ & & \\
\hline \multirow[t]{3}{*}{ dc $1.3 \mathrm{~V}$} & $\mathrm{Fe}^{0}(57)$ & $\mathrm{LiF}$ & $n-\mathrm{Fe}(56)$ \\
\hline & $\mathrm{Fe}^{2+}(41)$ & $\mathrm{Fe}$ & $\mathrm{Fe}^{2+}(23)$ \\
\hline & $\mathrm{Fe}^{3+}(2)$ & & $\mathrm{Fe}^{3+}(21)$ \\
\hline \multirow[t]{3}{*}{$\operatorname{ch} 4.3 \mathrm{~V}$} & $\mathrm{Fe}^{3+}(74)$ & & $a-\mathrm{FeF}_{3}(75)$ \\
\hline & $\mathrm{Fe}^{2+}(19)$ & & $n-\mathrm{FeF}_{2}$, int. (17) \\
\hline & $\mathrm{Fe}^{0}(8)$ & & $n-\mathrm{FeF}_{2}$, bulk (8) \\
\hline
\end{tabular}

$r$ : rhombohedral; $n$ : nanocrystalline; $a$ : amorph

During discharge (region a, b), Li is intercalated into the $\mathrm{HTB}^{-\mathrm{FeF}_{3}}$ structure up to a voltage of $2.0 \mathrm{~V}$ as has been observed previously, ${ }^{16}$ and is subsequently transformed into LiF and Fe nanoparticles when discharging to the cutoff voltage of 1.3V. During the Li intercalation process (a), reflections of HTB-FeF $F_{3}$ shift to lower $2 \theta$ values with a corresponding unit cell volume expansion of approx. $5 \%$ (Figure 6). The cell expansion is fairly linear up the end of the voltage plateau at approx. $2.5 \mathrm{~V}$, which is in agreement with a topotactical Li-insertion process described by Vegard's law. ${ }^{40}$ The XAS spectra of the Li-intercalation process (Figure 7a) show four isosbestic points characteristic for a two phase mixture consisting of $\mathrm{HTB}-\mathrm{FeF}_{3}$ and $\mathrm{HTB}-\mathrm{Li}_{x} \mathrm{FeF}_{3}$. At the end of the intercalation process, the $\mathrm{Fe}^{3+}$ peak 
(inset Figure 7a) has almost entirely disappeared and the iron atoms are mainly in a $\mathrm{Fe}^{2+}$ state corresponding to a fully intercalated $\mathrm{HTB}-\mathrm{Li}_{x} \mathrm{FeF}_{3}$ structure. From the PCA concentration profile (Figure 4) we calculated that $x=0.95 \mathrm{Li}$ at the end of the intercalation process, which is much larger than the maximum of $0.66 \mathrm{Li}$ for $\mathrm{HTB}^{-}-\mathrm{FeF}_{3} \cdot 0.33 \mathrm{H}_{2} \mathrm{O}$ found by the Maier group. ${ }^{16}$ We think this is

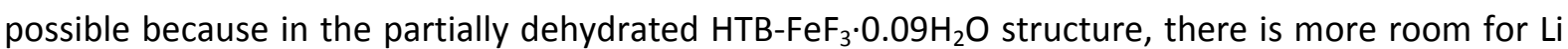
atoms available compared to $\mathrm{HTB}-\mathrm{FeF}_{3} \cdot 0.33 \mathrm{H}_{2} \mathrm{O}$ with $1 / 3$ of the channels already occupied by water molecules. The Mössbauer spectra (Figure 5) collected in the middle and end of region (a) (3.0 V and $1.9 \mathrm{~V}$, respectively), show a number of $\mathrm{Fe}^{2+}$ and $\mathrm{Fe}^{3+}$ doublets, which cannot be assigned unambiguously to any known iron fluoride phases to date. We assume that these doublets are due to Fe environments in partially lithiated $\mathrm{HTB}-\mathrm{Li}_{x} \mathrm{FeF}_{3}$. The $\mathrm{Fe}^{2+}$ doublets show a remarkable similarity with nanocrystalline $\mathrm{FeF}_{2}$ with one doublet for $\mathrm{Fe}$ atoms located at the interface of $\mathrm{FeF}_{2}$ particles and one doublet for Fe atoms in the bulk. ${ }^{38}$ However, there remains doubt if there is an additional phase transition from $\mathrm{HTB}-\mathrm{Li}_{x} \mathrm{FeF}_{3}$ to $n-\mathrm{FeF}_{2}$ before conversion because a) the quadrupole splitting (QS) of the $\mathrm{Fe}^{2+}$ doublets observed in our composite is slightly smaller than that observed for $n-\mathrm{FeF}_{2}$ (Table 3) and b) to date there is no comparable Mössbauer data for $\mathrm{HTB}^{-\mathrm{Li}_{x} \mathrm{FeF}} \mathrm{F}_{3}$ available in the literature. The $\mathrm{Fe}^{3+}$ doublets in the $3.0 \mathrm{~V}$ and $1.9 \mathrm{~V}$ spectra have an enlarged $\mathrm{QS}$ compared to pristine $\mathrm{HTB}^{-\mathrm{FeF}_{3}}$ $\left(0.58-0.64 \mathrm{~mm} \mathrm{~s}^{-1}\right)$ probably due to additional Li atoms in the channels.

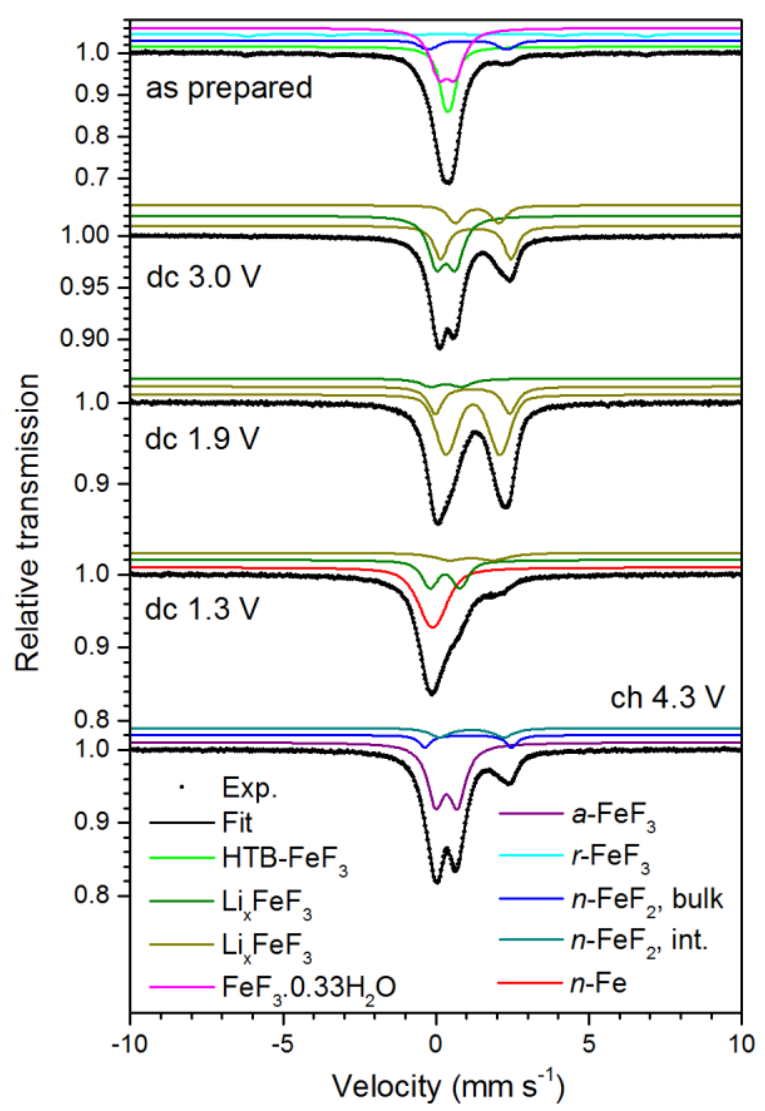


Figure 5: Mössbauer spectra of as prepared $\mathrm{HTB}-\mathrm{FeF}_{3} / \mathrm{rGO}$ (3) composite, discharged to $3.0 \mathrm{~V}, 1.9 \mathrm{~V}$ and $1.3 \mathrm{~V}$ and charged to $4.3 \mathrm{~V}$. The experimental spectrum is given as black dots and the total fit as a black line. Components of the fit are shown as coloured lines above the spectrum. The relative shift is given to $\alpha$-Fe.

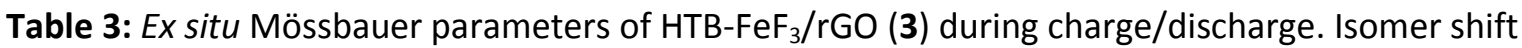
(IS), quadrupole splitting (QS), Lorentzian linewidth $(\Gamma)$ and hyperfine splitting (BHF). IS relative to $\alpha$ Fe. Reported values for known iron fluorides are given for comparison.

\begin{tabular}{|c|c|c|c|c|c|}
\hline & $\begin{array}{l}\text { IS } \\
\mathrm{mm} \mathrm{s}^{-1}\end{array}$ & $\begin{array}{l}\text { QS } \\
\mathrm{mm} \mathrm{s}^{-1}\end{array}$ & $\begin{array}{l}\Gamma \\
\mathrm{mm} \mathrm{s}^{-1}\end{array}$ & $\begin{array}{l}\text { BHF } \\
T\end{array}$ & $\begin{array}{l}\text { Area } \\
\%\end{array}$ \\
\hline \multirow[t]{4}{*}{ as prepared } & $0.47(1)$ & $0.54(18)$ & $0.67(10)$ & - & 61.9 \\
\hline & $0.50(2)$ & $0.22(2)$ & $0.46(7)$ & - & 28.0 \\
\hline & $1.14(2)$ & $2.56(3)$ & 0.4 & - & 7.0 \\
\hline & $0.46(1)$ & $0.01(3)$ & $0.41(5)$ & $40.4(1)$ & 3.0 \\
\hline \multirow[t]{3}{*}{ dc $3.0 \mathrm{~V}$} & $0.33(3)$ & $0.62(5)$ & $0.598(6)$ & - & 57.8 \\
\hline & $1.305(5)$ & $2.300(9)$ & $0.49(1)$ & - & 28.0 \\
\hline & $1.35(8)$ & $1.4(2)$ & $0.45(5)$ & - & 14.2 \\
\hline \multirow[t]{3}{*}{ dc $1.9 \mathrm{~V}$} & $1.321(2)$ & $1.76(2)$ & $0.31(4)$ & - & 46.0 \\
\hline & $1.302(2)$ & $2.434(6)$ & $0.56(2)$ & - & 33.9 \\
\hline & $0.43(1)$ & $1.02(1)$ & $0.81(3)$ & - & 20.0 \\
\hline \multirow[t]{3}{*}{ dc $1.3 \mathrm{~V}$} & 0 & - & $0.70(2)$ & - & 55.5 \\
\hline & $1.27(4)$ & $1.45(7)$ & $1.10(3)$ & - & 23.3 \\
\hline & $0.405(4)$ & $0.979(6)$ & 0.5 & - & 21.2 \\
\hline \multirow[t]{3}{*}{$\operatorname{ch} 4.3 \mathrm{~V}$} & $0.456(2)$ & $0.709(4)$ & $0.649(2)$ & - & 75.0 \\
\hline & $1.279(7)$ & $2.11(2)$ & $0.78(2)$ & - & 17.3 \\
\hline & $1.167(4)$ & $2.83(1)$ & $0.44(2)$ & - & 7.7 \\
\hline 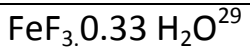 & $0.439(2)$ & $0.640(4)$ & $0.50(1)$ & - & - \\
\hline \multirow[t]{2}{*}{ HTB-FeF ${ }_{3}^{36}$} & $0.400(5)^{a}$ & $0.58(2)$ & $0.49(4)$ & - & $61(5)$ \\
\hline & $0.419(5)$ & $0.23(2)$ & $0.36(4)$ & & $39(5)$ \\
\hline$r-\mathrm{FeF}_{3}{ }^{37}$ & $0.474(6)$ & $0.05(1)$ & 0.246 & $40.4(2)$ & - \\
\hline$a-\mathrm{FeF}_{3}{ }^{41}$ & 0.48 & 0.58 & 0.45 & - & - \\
\hline $\mathrm{FeOF}^{42}$ & 0.397 & 1.18 & - & - & - \\
\hline $\mathrm{FeF}_{2}^{43}$ & 1.37 & 2.78 & 0.23 & - & - \\
\hline \multirow[t]{2}{*}{$n-\mathrm{FeF}_{2}{ }^{38}$} & 1.289 bulk & 2.733 & 0.352 & - & 75 \\
\hline & 1.267 int. & 1.968 & 0.550 & & 25 \\
\hline
\end{tabular}

${ }^{\mathrm{a}}$ IS converted from $100 \mathrm{~K}$ to 300

${ }^{\mathrm{b}} r$ : rhombohedral; $n$ : nanocrystalline; $a$ : amorphous

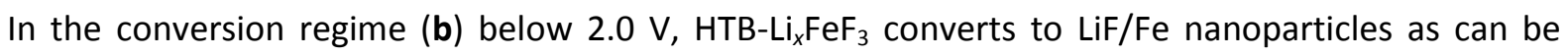
clearly seen by the appearance of a broad LiF/Fe peak in the XRD contour plot Figure 4 and the insitu XAS spectra (Figure 7b). The XAS spectra show another set of isosbestic points and a growing $\mathrm{Fe}^{0}$ peak (inset) indicating two phases in equilibrium (LiF cannot be seen by Fe-K edge XAS). The PCA concentration profile (Figure 4) shows that the cell after full discharge contains $63 \% \mathrm{Fe}^{2+}, 36 \% \mathrm{Fe}^{0}$

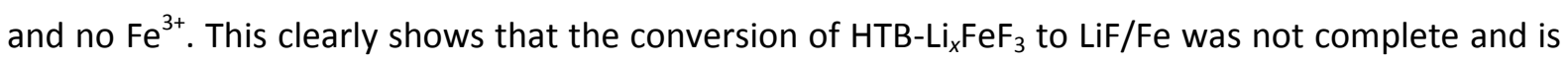
much slower compared to fast Li-intercalation process in the beginning of discharge. A second cell, 
which was discharged to $1.3 \mathrm{~V}$ prior to the synchrotron experiment, had a much higher Fe content of $57 \% \mathrm{Fe}^{0}$ and $41 \% \mathrm{Fe}^{2+}$ at the end of discharge and this cell was used in subsequent charge/discharge cycles (c-f). The ex-situ Mössbauer spectrum (Figure 5) collected after full discharge at $1.3 \mathrm{~V}$ shows a $\mathrm{Fe}^{0}$ singlet due to superparamagnetic Fe nanoparticles ${ }^{44,45}$ and two doublets for $\mathrm{Fe}^{2+}$ and $\mathrm{Fe}^{3+}$, respectively, which are due to unreacted $\mathrm{HTB}^{-\mathrm{Li}_{x}} \mathrm{FeF}_{3}$.
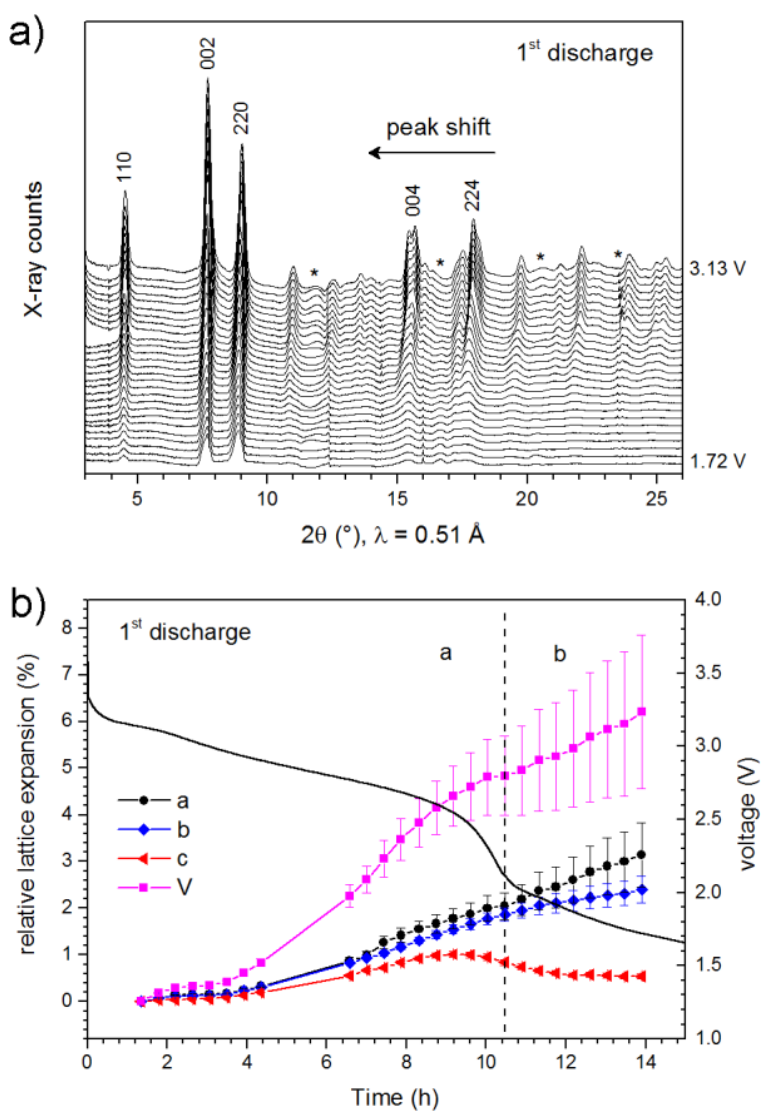

Figure 6: a) In situ X-ray diffraction patterns of $\mathrm{HTB}^{-\mathrm{FeF}_{3}} / \mathrm{rGO}$ (3) composite collected during $1^{\text {st }}$

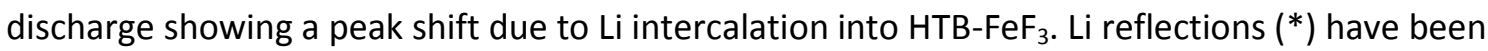
excluded for clarity. b) Relative lattice expansion calculated from refined lattice parameters of HTB$\mathrm{FeF}_{3}$ phase.

During charge (c, d), the LiF/Fe nanoparticles transform reversibly to $\mathrm{FeF}_{2}$ and $\mathrm{FeF}_{3} .{ }^{44}$ To the best of our knowledge, it has not been investigated which $\mathrm{FeF}_{2}$ or $\mathrm{FeF}_{3}$ polymorph will form when charging a previously discharged $\mathrm{HTB}-\mathrm{FeF}_{3}$ composite rather than the better investigated $r-\mathrm{FeF}_{3} / \mathrm{carbon}$ composites. The XRD diffraction data (Figure 4) did not show any new phases during charge indicating that the $\mathrm{FeF}_{2}$ and $\mathrm{FeF}_{3}$ particles are nanocrystalline with domain sizes below the coherent $\mathrm{X}$-ray scattering length. However, the transformation of $\mathrm{Fe}$ into $\mathrm{FeF}_{2}$ and $\mathrm{FeF}_{3}$ is clearly visible in the PCA concentration profile. In the beginning of the charge process (c), the amount of $\mathrm{Fe}^{2+}$ increases 
indicating formation of $\mathrm{FeF}_{2}$, and above $3.87 \mathrm{~V}$ (region $\mathrm{d}$ ) the $\mathrm{Fe}^{2+}$ concentration decreases fast with concomitant oxidation and formation of $\mathrm{FeF}_{3}$. The Mössbauer spectrum collected after full charge at 4.3 $\mathrm{V}$ (Figure 5) shows a large $\mathrm{Fe}^{3+}$ doublet, which is in good agreement with amorphous $\mathrm{FeF}_{3}$. Due to the very small particles we do not observe a hyperfine splitting as would be expected for ferromagnetic $r-\mathrm{FeF}_{3}$. The spectrum also contains two $\mathrm{Fe}^{2+}$ doublets, one with a small QS of $2.11 \mathrm{~mm}$ $\mathrm{s}^{-1}$ and one with a large QS of $2.83 \mathrm{~mm} \mathrm{~s}^{-1}$, which are in good agreement with nanocrystalline $\mathrm{FeF}_{2}$ (Table 3). This is evidence that the charge process does not go via the HTB-framework structure forming $\mathrm{HTB}_{\mathrm{Li}} \mathrm{LeF}_{3}$, but rather through the formation of rutile $\mathrm{FeF}_{2}$ and rhomobohedral $\mathrm{FeF}_{3}$ phases as has been observed for other $r-\mathrm{FeF}_{3} /$ carbon composites.
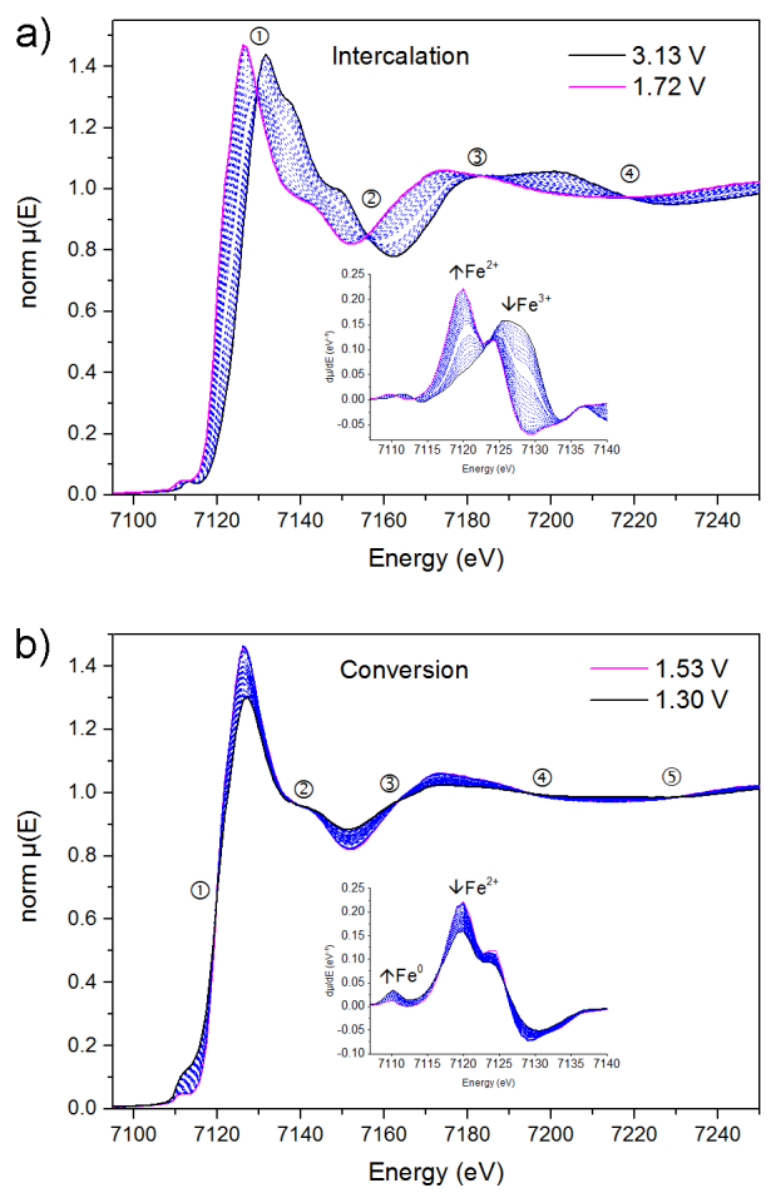

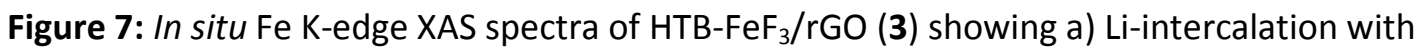
characteristic isosbestic points (marked with numbers 1-4). The inset shows the derivative spectra with increasing $\mathrm{Fe}^{2+}$ and decreasing $\mathrm{Fe}^{0}$ peak intensity. b) Conversion of $\mathrm{HTB}^{-\mathrm{FeF}_{3}}$ into LiF and Fe indicated by a second set of isosbestic points. 


\section{Conclusion}

We have synthesised $\mathrm{HTB}-\mathrm{FeF}_{3} / \mathrm{rGO}$ (and $r-\mathrm{FeF}_{3} / \mathrm{rGO}$ ) composite materials as a high energy cathode for Li-ion batteries from graphene oxide suspension and commercial $\mathrm{FeF}_{3}$ using a HF-free and

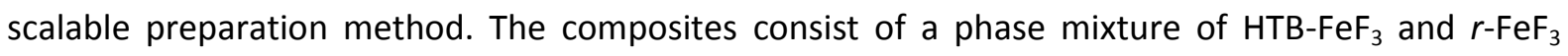
polymorphs depending on ball milling conditions and temperature during reduction process. HTB$\mathrm{FeF}_{3} / \mathrm{rGO}$ composites show a stable discharge capacity of $400-450 \mathrm{mAh} / \mathrm{g}$ at $55^{\circ} \mathrm{C}$ vs. Li metal anode and a remarkably good cycle stability over 100 cycles. The good cycle performance was attributed to the microstructure, which consists of $\mathrm{FeF}_{3}$ particles covered entirely by reduced graphene oxide layers. The stable carbon coating of hygroscopic $\mathrm{FeF}_{3}$ particles permits the preparation of high quality electrodes without the need of moisture protection in ambient air and maintains electronic as well as Li ionic conductivity during prolonged cycling. The detailed reaction mechanism was investigated using a combination of in situ XAS, XRD and ex situ Mössbauer spectroscopy. Upon discharge, $\mathrm{Li}$ is inserted fast into the $\mathrm{HTB}-\mathrm{FeF}_{3}$ tunnel structure followed by a slow conversion reaction to LiF/Fe nanoparticles. Upon charge, $\mathrm{LiF} / \mathrm{Fe}$ is slowly converted back to rutile $\mathrm{FeF}_{2}$ and

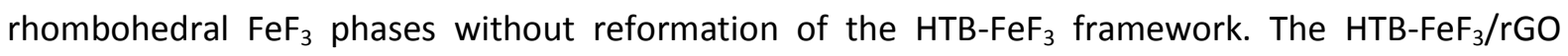
material is able to deliver a high specific energy of 700-800 Wh/kg at elevated temperature and slow rates, but the energy density is reduced at higher rates due to kinetic limitations of the conversion reaction. A solid or liquid electrolyte suitable for cycling the material above $100^{\circ} \mathrm{C}$ might be a way to improve the energy density and rate capability of $\mathrm{HTB}-\mathrm{FeF}_{3} / \mathrm{rGO}$ significantly.

\section{Acknowledgements}

The authors would like to thank the European Synchrotron Radiation Facility (ESRF) for granting beam time for the in situ XAS/XRD experiment. We also thank C. Ly for providing ICP-OES analytical service at the Karlsruhe Institute of Technology (FM-VEA). A. G. and V. S. would like to thank the Ministry of Education and Science of Russia for the financial support (agreement № 14.587.21.0002, identifier RFMEFI58714X0002). Financial support by EU-RTD "Hi-C" (Novel in situ and in operando techniques for characterization of interfaces in electrochemical storage systems") in the $7^{\text {th }} \mathrm{FP}$, grant agreement no. 608575 is gratefully acknowledged.

Supporting Information Available: Synthesis of aqueous graphene oxide and $\mathrm{FeF}_{3} / \mathrm{rGO}$ composite material, electrode preparation, EDX maps, $\mathrm{FeF}_{3}$ pore size distribution, $\mathrm{N}_{2}$ physisorption isotherm, XPS, TGA/DSC/MS analysis, Fe K-edge XANES PCA analysis and reference spectra. This material is available free of charge via the Internet at http://pubs.acs.org 


\section{References}

(1) Fichtner, M. Conversion Materials for Hydrogen Storage and Electrochemical applicationsConcepts and Similarities. J. Alloys Compd. 2011, 509, S529-S534.

(2) DOE Annual Merit Review 2012, http://www.annualmeritreview.energy.gov.

(3) Andre, D.; Kim, S.-J.; Lamp, P.; Lux, S. F.; Maglia, F.; Paschos, O.; Stiaszny, B. Future Generations of Cathode Materials: An Automotive Industry Perspective. J. Mater. Chem. A 2015, 3, 6709-6732.

(4) Fichtner, M. Konversionsmaterialien für die Energiespeicherung. Chemie unserer Zeit 2013, 47 (4), 230-238.

(5) Cabana, J.; Monconduit, L.; Larcher, D.; Palacín, M. R. Beyond Intercalation-Based Li-lon Batteries: The State of the Art and Challenges of Electrode Materials Reacting through Conversion Reactions. Adv. Mater. 2010, 22 (35), E170-E192.

(6) Wang, F.; Yu, H.-C.; Chen, M.-H.; Wu, L.; Pereira, N.; Thornton, K.; Van der Ven, A.; Zhu, Y.; Amatucci, G. G.; Graetz, J. Tracking Lithium Transport and Electrochemical Reactions in Nanoparticles. Nat. Commun. 2012, 3, 1201.

(7) Li, H.; Balaya, P.; Maier, J. Li-Storage via Heterogeneous Reaction in Selected Binary Metal Fluorides and Oxides. J. Electrochem. Soc. 2004, 151 (11), A1878.

(8) Conte, D. E.; Pinna, N. A Review on the Application of iron(III) Fluorides as Positive Electrodes for Secondary Cells. Mater. Renew. Sustain. Energy 2014, 3 (4), 37.

(9) Badway, F.; Cosandey, F.; Pereira, N.; Amatucci, G. G. Carbon Metal Fluoride Nanocomposites. J. Electrochem. Soc. 2003, 150 (10), A1318-A1327.

(10) Zhao, X.; Hayner, C. M.; Kung, M. C.; Kung, H. H. Photothermal-Assisted Fabrication of Iron Fluoride-Graphene Composite Paper Cathodes for High-Energy Lithium-Ion Batteries. Chem. Commun. 2012, 48 (79), 9909-9911.

(11) Liu, J.; Wan, Y.; Liu, W.; Ma, Z.; Ji, S.; Wang, J.; Zhou, Y.; Hodgson, P.; Li, Y. Mild and CostEffective Synthesis of Iron Fluoride-graphene Nanocomposites for High-Rate Li-Ion Battery Cathodes. J. Mater. Chem. A 2013, 1 (6), 1969.

(12) Ma, R. G.; Lu, Z. G.; Wang, C. D.; Wang, H. E.; Yang, S. L.; Xi, L. J.; Chung, J. C. Y. Large-Scale Fabrication of Graphene-Wrapped FeF3 Nanocrystals as Cathode Materials for Lithium Ion Batteries. Nanoscale 2013, 5 (14), 6338-6343.

(13) Chu, Q.; Xing, Z.; Ren, X.; Asiri, A. M.; Al-Youbi, A. O.; Alamry, K. A.; Sun, X. Reduced Graphene Oxide Decorated with FeF3 Nanoparticles: Facile Synthesis and Application as a High Capacity Cathode Material for Rechargeable Lithium Batteries. Electrochim. Acta 2013, 111, 80-85.

(14) Ma, R.; Dong, Y.; Xi, L.; Yang, S.; Lu, Z.; Chung, C. Fabrication of LiF/Fe/Graphene Nanocomposites as Cathode Material for Lithium-Ion Batteries. ACS Appl. Mater. Interfaces 2013, 5 (3), 892-897. 
(15) Li, C.; Gu, L.; Tsukimoto, S.; van Aken, P. a; Maier, J. Low-Temperature lonic-Liquid-Based Synthesis of Nanostructured Iron-Based Fluoride Cathodes for Lithium Batteries. Adv. Mater. 2010, 22 (33), 3650-3654.

(16) Li, C.; Gu, L.; Tong, J.; Tsukimoto, S.; Maier, J. A Mesoporous Iron-Based Fluoride Cathode of Tunnel Structure for Rechargeable Lithium Batteries. Adv. Funct. Mater. 2011, 21 (8), 13911397.

(17) Li, C.; Gu, L.; Tong, J.; Maier, J. Carbon Nanotube Wiring of Electrodes for High-Rate Lithium Batteries Using an Imidazolium-Based Ionic Liquid Precursor as Dispersant and Binder: A Case Study on Iron Fluoride Nanoparticles. ACS Nano 2011, 5 (4), 2930-2938.

(18) Li, C.; Mu, X.; van Aken, P. A.; Maier, J. A High-Capacity Cathode for Lithium Batteries Consisting of Porous Microspheres of Highly Amorphized Iron Fluoride Densifi Ed from Its Open Parent Phase. Adv. Energy Mater. 2013, 3 (1), 113-119.

(19) Li, C.; Yin, C.; Mu, X.; Maier, J. Top-down Synthesis of Open Framework Fluoride for Lithium and Sodium Batteries. Chem. Mater. 2013, 25 (6), 962-969.

(20) Wang, F.; Kim, S.; Seo, D.; Kang, K.; Wang, L.; Su, D.; Vajo, J. J.; Wang, J.; Graetz, J. Ternary Metal Fluorides as High-Energy Cathodes with Low Cycling Hysteresis. Nat. Commun. 2015, 6, $1-9$.

(21) Pohl, A. H.; Guda, A. A.; Shapovalov, V. V.; Witte, R.; Das, B.; Scheiba, F.; Rothe, J.; Soldatov, A. V.; Fichtner, M. Oxidation State and Local Structure of a High-Capacity LiF/Fe(V2O5) Conversion Cathode for Li-Ion Batteries. Acta Mater. 2014, 68, 179-188.

(22) Rourke, J. P.; Pandey, P. a; Moore, J. J.; Bates, M.; Kinloch, I. a; Young, R. J.; Wilson, N. R. The Real Graphene Oxide Revealed: Stripping the Oxidative Debris from the Graphene-like Sheets. Angew. Chem. Int. Ed. Engl. 2011, 50 (14), 3173-3177.

(23) Coelho, A. A. TOPAS-Academic V4.1. Coelho Software: Brisbane, Australia 2007.

(24) Hammersley, A. P.; Svensson, S. O.; Hanfland, M.; Fitch, A. N.; Hausermann, D. TwoDimensional Detector Software: From Real Detector to Idealised Image or Two-Theta Scan. High Press. Res. 1996, 14 (4-6), 235-248.

(25) Beale, A. M.; Le, M. T.; Hoste, S.; Sankar, G. A Time Resolved in Situ Investigation into the Formation of Bismuth Molybdate Catalysts Prepared by Spray-Dried Methods. Solid State Sci. 2005, 7 (10), 1141-1148.

(26) Coulston, G. W. The Kinetic Significance of V5+ in N-Butane Oxidation Catalyzed by Vanadium Phosphates. Science 1997, 275 (5297), 191-193.

(27) Smolentsev, G.; Soldatov, a. V. Fitlt: New Software to Extract Structural Information on the Basis of XANES Fitting. Comput. Mater. Sci. 2007, 39 (3), 569-574.

(28) Leblanc, M.; Pannetier, J.; Ferey, G.; de Pape, R. Single Crystal Refinement of the Structure of Rhombohedral FeF3. Rev. Chim. Miner. 1985, 22, 107-114. 
(29) Leblanc, M.; Ferey, G.; Chevallier, P.; Calage, Y.; De Pape, R. Hexagonal Tungsten Bronze-Type Felll Fluoride: (H2O)0.33FeF3; Crystal Structure, Magnetic Properties, Dehydration to a New Form of Iron Trifluoride. J. Solid State Chem. 1983, 47 (1), 53-58.

(30) Täubert, C.; Fleischhammer, M.; Wohlfahrt-Mehrens, M.; Wietelmann, U.; Buhrmester, T. $\mathrm{LiBOB}$ as Electrolyte Salt or Additive for Lithium-Ion Batteries Based on LiNi0.8Co0.15Al0.05O2/Graphite. J. Electrochem. Soc. 2010, 157 (6), A721.

(31) Illig, J. Physically Based Impedance Modelling of Lithium-Ion Cells; KIT Scientific Publishing: Karlsruhe, 2014.

(32) Ko, J. K.; Wiaderek, K. M.; Pereira, N.; Kinnibrugh, T. L.; Kim, J. R.; Chupas, P. J.; Chapman, K. W.; Amatucci, G. G. Transport, Phase Reactions, and Hysteresis of Iron Fluoride and Oxyfluoride Conversion Electrode Materials for Lithium Batteries. ACS Appl. Mater. Interfaces 2014, 6 (14), 10858-10869.

(33) Huh, S. H.; Choi, S.-H.; Ju, H.-M.; Kim, D.-H. Properties of Interlayer Thermal Expansion of 6Layered Reduced Graphene Oxide. J. Korean Phys. Soc. 2014, 64 (4), 615-618.

(34) Trucano, P.; Chen, R. Structure of Graphite by Neutron Diffraction. Nature. 1975, pp 136-137.

(35) Stankovich, S.; Piner, R. D.; Chen, X.; Wu, N.; Nguyen, S. T.; Ruoff, R. S. Stable Aqueous Dispersions of Graphitic Nanoplatelets via the Reduction of Exfoliated Graphite Oxide in the Presence of Poly(sodium 4-Styrenesulfonate). J. Mater. Chem. 2006, 16 (2), 155.

(36) Calage, Y.; Leblanc, M.; Ferey, G.; Varret, F. Mössbauer Investigation of Hexagonal Tungsten Bronze Type Felll Fluorides: (H2O)0.33 FeF3 and Anhydrous FeF3. J. Magn. Magn. Mater. 1984, pp 195-203.

(37) Wertheim, G. K.; Guggenheim, H. J.; Buchanan, D. N. E. Sublattice Magnetization in FeF3 near the Critical Point. Phys. Rev. 1968, 169 (2), 465-470.

(38) Ramasamy, S.; Jiang, J.; Gleiter, H.; Birringer, R.; Gonser, U. Investigation of Nanocrystalline FeF2 by Mössbauer Spectroscopy. Solid State Commun. 1990, 74 (8), 851-855.

(39) Matteazzi, P.; Caër, G. Le. Exchange Reaction Milling in Iron Nitrides, Fluorides and Carbides. J. Alloys Compd. 1992, 187 (2), 305-315.

(40) Denton, A. R.; Ashcroft, N. W. Vegards Law. Phys. Rev. A 1991, 43 (6), 3161-3164.

(41) Grenèche, J. M.; Varret, F. Mössbauer Effect Studies of Iron Fluorides. In Mössbauer Spectroscopy Applied to Magnetism and Materials Science; Long, G. J., Grandjean, F., Eds.; 1993; pp 161-203.

(42) Chappert, J.; Portier, J. Effet Mössbauer Dans FeOF. Solid State Commun. May 1966, pp 185188.

(43) Greenwood, N. N.; Howe, A. T.; Ménil, F. Mössbauer Studies of Order and Disorder in Rutile and Trirutile Compounds Derived from FeF2. J. Chem. Soc. A Inorganic, Phys. Theor. 1971, 2218. 
(44) Wang, F.; Robert, R.; Chernova, N. a; Pereira, N.; Omenya, F.; Badway, F.; Hua, X.; Ruotolo, M.; Zhang, R.; Wu, L.; Volkov, V.; Su, D.; Key, B.; Whittingham, M. S.; Grey, C. P.; Amatucci, G. G.; Zhu, Y.; Graetz, J. Conversion Reaction Mechanisms in Lithium lon Batteries: Study of the Binary Metal Fluoride Electrodes. J. Am. Chem. Soc. 2011, 133 (46), 18828-18836.

(45) Christensen, P. H.; Moerup, S.; Niemantsverdriet, J. W. Particle Size Determination of Superparamagnetic a-Fe in Carbon-Supported Catalysts by in Situ Moessbauer Spectroscopy. J. Phys. Chem. 1985, 89 (23), 4898-4900. 